\title{
EDITORIAL
}

\section{HISTÓRIA, LAICIDADE E ATEÍSMO EM UM OLHAR INTERDISCIPLINAR}

\author{
Editorial \\ History, Laicity and Atheism in an interdisciplinary view
}

O presente número (v. 09, n. 02) da revisa Relegens Thréskeia apresenta um dossiê temático intitulado História, laicidade e ateísmo com um total de oito artigos, uma seção com sete artigos de tema livre de fluxo contínuo e duas resenhas. Os trabalhos selecionados trazem a marca da interdisciplinaridade que caracteriza a linha editorial da revista. Contudo, podemos dizer que esse número da revista inova ao abrir espaço para um tema ainda pouco usual nas pesquisas acadêmicas brasileiras: o ateísmo. Analisar o fenômeno da descrença religiosa, seja sob o âmbito da história, da sociologia ou das ciências da religião, assim como fornecer um material que auxilie futuros pesquisadores, é o principal legado dessa edição da Relegens Thréskeia.

O dossiê temático começa com o artigo $\mathbf{O}$ ateísmo na historiografia, de autoria de Ricardo Oliveira da Silva. Esse trabalho destaca um panorama da produção historiográfica sobre o ateísmo e procura defender o potencial desse tipo de pesquisa para os historiadores brasileiros. Com esse objetivo são mostrados inicialmente algumas investigações na historiografia estrangeira (até como forma de estimular os pesquisadores nacionais) e a exposição de alguns estudos nas universidades brasileiras.

Em Sociologia do ateísmo, artigo de Fernando Mezadri, é feita a apresentação de elementos conceituais e pistas interpretativas em vista da tematização do ateísmo enquanto fenômeno para investigações sociológicas, tendo os clássicos da sociologia como referência. $\mathrm{O}$ objetivo do texto é oferecer um modo de interpretação de alguns textos dos sociólogos clássicos em vista da extração de indícios que levem a explicações do fenômeno do ateísmo enquanto um tipo da irreligiosidade humana. A metodologia adotada no artigo é bibliográfica e interpretativa e as contribuições obtidas com este estudo apontam para o entendimento de que, mesmo não tratando do ateísmo propriamente dito, os clássicos da sociologia - ao abordarem a religião como janela compreensiva da modernidade -, deixaram uma possibilidade para estudo da descrença e outros tipos de irreligiosidade.

No artigo A crítica neoateísta à influência da religião na política nas sociedades contemporâneas, Roney de Seixas Andrade analise a crítica presente no discurso neoateísta em relação à influência da religião na política no âmbito das sociedades contemporâneas em 
geral e na sociedade estadunidense em particular. De acordo com o autor, o presente artigo visa discutir o estreito relacionamento entre religião e política e as suas permanentes conexões, uma vez que, diferente daquilo que convencionalmente se pensa, a religião não se reduz a crenças, a ritos e a práticas associadas, antes e primordialmente, a religião é política, isto é, ela está relacionada ao ordenamento do mundo humano-social.

Ricardo Cortez Lopes e Yana de Lima Martinez, em Um estudo sobre o ateísmo no anarquismo: análise da peça teatral "o semeador", de Avelino Fóscolo, reflete sobre um ateísmo anarquista por meio da literatura, mais precisamente na peça $\mathrm{O}$ semeador, de Avelino Fóscolo. A obra foi analisada com base em quatro temas: Deus (como a divindade católica é retratada?), Vigário (como ele é apresentado na peça?), Religião (como princípios religiosos são retratados?) e Fiel (Como é retratado um religioso?). Os resultados apontaram para um enredo pautado no ateísmo de aposta: Deus aparece como um engano que serve exclusivamente para manter a desigualdade, e isso fica demonstrado a posteriori se ocorrer a revolução anarquista.

Em Laicidade em disputa: um estudo a partir da aprovação do ensino religioso confessional no STF, Luiz Eduardo Valiengo Berni realiza uma análise dos modelos de laicidade em disputa no Estado brasileiro, a partir dos votos, do relator e revisor, no Supremo Tribunal Federal (STF), no julgamento da Ação Direta de Inconstitucionalidade (ADI - 4439, de 2010). De acordo com ele, os resultados apontam para paradoxos no modelo de laicidade brasileira. Conclui-se que existem dois modelos em disputa (laicidade com total separação estado e igreja; e laicidade com a colaboração igreja-estado); com adoção do Ensino Religioso Confessional oficializado, ampliam-se riscos à manutenção da diversidade religiosa, sobretudo dos grupos minoritários.

Rodrigo Marques Leistner e Alexsandro Teixeira de Aguiar, em A polêmica da sacralização de animais nos terreiros afro-brasileiros e os percursos da laicidade no Brasil, abordam as lógicas de presença das religiões afro-brasileiras na esfera pública do país, avaliando-se algumas características da laicidade no Brasil e observando tais realidades a partir de um caso emblemático: a polêmica da sacralização de animais em rituais religiosos de matriz africana. Uma polêmica que se desenvolve desde 2003, quando um Projeto de Lei estadual visou proibir as práticas de imolação em rituais religiosos no Rio Grande do Sul. Desde então, o embate adquiriu dimensão nacional, sendo diversas as contendas jurídicas ativadas em torno do tema. 
O "ateísmo new age"? moralidade e espiritualidade em Sam Harris é o artigo de autoria de Danilo Monteiro Firmino, no qual esse historiador investiga as relações entre o pensamento do filósofo e neurocientista ateu Sam Harris e as práticas conhecidas como Nova Era (New Age). Em sua busca pela moralidade e espiritualidade longe da influência religiosa e baseada na ciência, o neurocientista pauta suas discussões em elementos e discussões recorrentes de círculos New Age, um entrecruzamento do esoterismo europeu com religiões orientais.

E, finalizando os artigos da seção dossiê, temos Conflito entre ciência e religião em Gould, Harris e Dawkins. Esse texto é da autoria de Rogério Fernandes Silva, o qual busca destacar dois lados antagônicos de um debate: a tese do conflito entre ciência e religião na construção de uma identidade ateia. A criação e divulgação da tese de conflito tem respaldo nas obras neoateístas, sendo importantes tanto os posicionamentos mais favoráveis à religião neste caso, as afirmações de Stephen Jay Gould, que luta contra os aspectos negativos da tese - quanto, por outro lado, os dos pensadores ateus - como Sam Harris e Richard Dawkins, que estão contra as afirmações de Gould, como se a tese de conflito fosse parte da identicidade ateísta.

A seção de artigos com tema livre começa com "Irradiar o sopro do espírito sobre o mundo": sentidos da pesquisa sociológica no catolicismo carismático, de autoria de Emanuel Freitas da Silva. Trata-se de uma análise acerca dos sentidos conferidos por atores do campo religioso à pesquisas que versam sobre seus modos de vida, buscando compreender as ideias feitas por eles acerca de um saber (a pesquisa sociológica), que se pretende construir acerca das formas de experiência do religioso por eles vivenciada, tomando como córpus de análise o universo da Comunidade Católica Shalom, oriunda do catolicismo carismático e sediada em Fortaleza (CE).

Elizete da Silva, em Judeus, católicos e protestantes na terra do açúcar: afinidades e divergências, investiga as redes de sociabilidade e solidariedade entre judeus, cristãos-novos e protestantes na América Portuguesa no século XVI e XVII. De acordo com ela, a historiografia colonial raramente tem tratado das religiões que construíram a cultura brasileira, tampouco dos intercursos religiosos e da presença protestante. Para realizar esse propósito são abordados no artigo os primeiros séculos da colonização, particularmente o período designado como Brasil holandês (1630-1654), quando se estreitaram essas relações, com a permissão de funcionamento de sinagogas e cemitérios judaicos pela Companhia das Índias Ocidentais, de orientação calvinista. 
No artigo Curandeirismo no Brasil: uma abordagem histórico-jurídica na transição para a República, Ludimila Caliman Campos, Lara Ferreira Lorenzoni e Aline Magdalão da Fonseca Lima, abordam a prática do curandeirismo no Brasil sob um viés histórico-jurídico, apresentando como recorte temporal a transição do final do Império e os primórdios da República. Essa temporalidade abrange um período marcado pela formação de uma intelectualidade influenciada pelas convicções do positivismo, que buscava trazer para o Brasil ideias de progresso, ordem e formação de nação. No bojo dessa intelectualidade, estavam os médicos e farmacêuticos, que lutaram por sua hegemonia e procuraram combater todas as práticas que não tivessem a chancela da ciência. Ao mesmo tempo, a Igreja Católica buscava garantir uma hegemonia religiosa. Como consequência, a República inaugura o Código Penal de 1890, de modo a criminalizar quaisquer práticas espíritas, estando o curandeirismo nesse bojo.

Crislaine Pereira de Lima, Cristina Satiê de Oliveira Pátaro e Frank Antonio Mezzomo, em Mulheres na política: a participação de candidatas religiosas à ALEP (2018), realizam um estudo onde buscam analisar a participação de mulheres na campanha eleitoral à Assembleia Legislativa Estadual do Paraná nas eleições de 2018, atentando-se especificamente às pleiteantes que fizeram uso, em sua campanha, de elementos religiosos. As autoras procuram evidenciar, a partir dos materiais de campanha que circularam no Facebook oficial das candidatas, a recorrência ao imaginário, símbolos e outros elementos religiosos, sobretudo no que diz respeito às pautas de campanha que evidenciam esta relação entre os campos político e religioso.

Em Notas sobre alguns documentos inexplorados para a história de Angola: os róis dos confessados de 1704, de autoria de José C. Curto, é analisado uma fonte quantitativa que tem sido utilizada por historiadoras(es) nas últimas décadas, os róis ou arrolamentos de confessados. No caso particular de Angola, esta documentação contém informações demográficas dos indivíduos e da(s) família(s) que habitavam os fogos pertencentes às freguesias do Bispado de Angola, no ano de 1704. Tendo como finalidade listar os fregueses que haviam cumprido seus deveres religiosos, o rol de confessados de 1704 não só permite melhor compreender as estruturas de populações que antecederam o desenvolvimento de recenseamentos, no final do século XVIII, mas, também, possibilita investigar os padrões de família, de habitação, de riqueza ou pobreza dos moradores e soldados e, especialmente, o número de escravos que esses indivíduos possuíam. Esta contribuição descreve essas possibilidades, com foco no presídio de Muxima. 
No artigo Usos, significados e conservação da planta espada de são Jorge, sansevieria zeylanica, na comunidade quilombola Benevides, São Domingos do CapimPA-Brasil, Adão Souza Borges aborda a relação da biodiversidade com os sujeitos amazônicos que protagonizam e resistem em prol do uso coletivo dos recursos naturais, quando a linguagem e os significados se enquadram em elementos de resistência, porque transitam no campo do sagrado. Além disso, o artigo busca compreender os usos, os significados e as formas de conservação da planta Espada de São Jorge (Sansevieria zeylanica) pelos quilombolas da comunidade Benevides, em Aurora do Pará, Brasil.

Luiz Ernesto Guimarães, Antônio Mendes da Costa Braga, Fabio Lanza e Luan Prado Piovani, em Conflitos agrários e o catolicismo liberacionista: Romaria da Terra (PR, SC) e os arquivos do SNI, apresentam reflexões acerca do conflito agrário no Brasil e sua relação com grupos religiosos católicos, sob a perspectiva liberacionista. Para realizar esse objetivo foram selecionados de forma intencional dois períodos da história recente do Brasil com o mesmo recorte territorial (PR e SC), seja no período da ditadura militar (1964-1985) a partir da investigação documental nos arquivos que foram publicizados pelo Serviço Nacional de Informação (SNI) ou no século XXI considerando a pesquisa de campo em evento católico intitulado Romaria da Terra e das Águas (2015 - SC). Frente aos diferentes contextos foram elaboradas as seguintes questões: quais são as principais características dessa relação entre grupos e lideranças católicas e o enfrentamento da estrutura fundiária concentradora? Como os diferentes períodos da história nacional são evidenciados pelas fontes frente ao tema do conflito agrário e às ações católicas vinculadas a Teologia da Libertação? Como resultado os autores identificaram que o caráter contestatório que as respectivas manifestações religiosas tiveram contra o latifúndio e o papel desempenhado pela CPT para auxiliar na organização dos camponeses, fez com que fosse vigiada pelos órgãos de segurança durante a ditadura militar brasileira (1964 - 1985). Ainda, os simbolismos das romarias na atualidade, além de sua especificidade de representar e relembrar os episódios de luta pela terra, marcam o processo histórico por uma sociedade com menor desigualdade na distribuição agrária.

Por fim, a revista Relegens Thréskeia (v. 09, n. 02) conta com duas resenhas. A primeira é da autoria de Willian Perpétuo Busch e versa sobre o livro A History of Exorcism in Catholic Christianity, de Francis Young, publicado pela Palgrave Macmillan em 2016, como parte da série Palgrave Historical Studies in Witchcraft and Magic. Conforme destacado, o livro se propôs a realizar extensa análise da história do exorcismo no Cristianismo, com foco no pensamento teológico católico. Dividida em nove capítulos, o autor da resenha ressalta que 
a obra partiu de uma discussão geral sobre o conceito de exorcismo nos debates contemporâneos para ceder espaço a uma análise histórica que mobiliza três categorias analíticas: I) na interface entre teologia e saúde mental; II) experiências sacerdotais; III) representações oficiais e populares.

A segunda resenha é de Diego Omar Silveira. Intitulada Ensaios para uma história do ateísmo no Brasil, o autor faz uma apresentação crítica do livro O ateísmo no Brasil: os sentidos da descrença nos séculos XX e XXI, publicado pelo historiador Ricardo Oliveira da Silva em 2020. Segundo Diego Omar Silveira, os estudos da religião não avançam de modo uniforme, deixando lacunas como é o caso do ateísmo no Brasil. Ajudar a preencher essa lacuna seria a tarefa do livro $O$ ateísmo no Brasil, o qual, tomando como referência os anarquistas e comunistas brasileiros do século XX, e o ativismo ateísta do início do século XXI, busca fornecer ao leitor um panorama bibliográfico suficientemente amplo, de tal modo que tenhamos uma dimensão historiográfica dos assuntos, e analisar algumas fontes (jornais, revistas, sites ateístas, estatuto das associações e entrevistas com lideranças), como exercício de análise histórica sobre como diferentes homens/mulheres ateus/ateias se articularam para expor publicamente seus pontos de vista, quase sempre em choque com o catolicismo hegemônico (e seus agentes institucionais) ou com um Estado imbricado, na maior parte do tempo, com as pautas religiosas.

Na certeza de que os leitores encontrarão neste dossiê e nos artigos de fluxo contínuo uma oportunidade de leitura e aprofundamento em seus estudos e pesquisas, desejamos a todos boa leitura.

Cordialmente.

\section{Marcos Vinicius de Freitas Reis}

Doutor em Sociologia pela Universidade Federal de São Carlos (UFSCAR). Docente do Curso de Mestrado Acadêmico em História Social, do Curso de Mestrado Profissional Ensino de História e do Curso de Graduação em Relações Internacionais e História da Universidade Federal do Amapá (UNIFAP). E-mail: marcosvinicius5@yahoo.com.br

\section{Ricardo Oliveira da Silva}

Doutor em História pela Universidade Federal do Rio Grande do Sul (UFRGS). Docente do Curso de História da Universidade Federal do Mato Grosso do Sul, campus de Nova Andradina (UFMS/CPNA). E-mail: ricardorussell@gmail.com 